\title{
LIDAR COM SUBSTÂNCIAS PSICOATIVAS: O SIGNIFICADO PARA O TRABALHADOR DE ENFERMAGEM ${ }^{1}$
}

\author{
Elizabeth Rose Costa Martins ${ }^{2}$ \\ Adriana Kátia Corrêa ${ }^{3}$
}

Martins ERC, Corrêa AK. Lidar com substâncias psicoativas: o significado para o trabalhador de enfermagem. Rev Latino-am Enfermagem 2004 março-abril; 12(número especial):398-405.

Neste estudo propus-me a compreender o significado do lidar com substâncias psicoativas para os trabalhadores de enfermagem que atuam em clínica médica de uma unidade hospitalar. Para alcançar tal propósito, foram utilizadas idéias do referencial metodológico fenomenológico. Foram feitas entrevistas a partir da questão norteadora "o que é para você lidar com substâncias psicoativas?". A análise das falas revelou que esse lidar se mostra aos trabalhadores, em sua essência, um trabalho "como qualquer outro", sendo significativa a ênfase dada ao fazer em detrimento da prática reflexiva; o receio de falar sobre "o proibido", o que "compromete", sendo a droga enfocada como uma possibilidade real de uso no cotidiano dos trabalhadores. Suas experiências reafirmam a necessidade de refletir e discutir sobre o fenômeno drogas, articulando as vivências intersubjetivas ao contexto das Políticas Nacionais e Internacionais de Saúde, favorecendo aos profissionais perceberem de forma mais crítica e questionadora o fenômeno.

DESCRITORES: trabalhador de enfermagem; saúde; substância psicoativa; enfermagem

\section{DEALING WITH PSYCHOACTIVE SUBSTANCES: THE MEANING FOR NURSING WORKERS}

This study $i$ have proposed to understand the meaning of dealing with psychoactive substances for nursing workers who work at a medical clinic at a hospital unit. For that, some ideas of phenomenological methodological reference have been used. Interviews have been made from the guiding question" what is dealing with psychoactive substances for you?. The speeches analysis, revealing that this dealing shows itself to workers, in its essence, a job "as any other", being the emphasis given to doing regarding to reflexive praxis, significant; the fear of talking about" the forbidden", what "compromises" as drugs is focused as a real possibility of use in the workers daily life. This experiences re-affirm the need of reflecting about the drug phenomenon working the inter-subjective experiences to the context of National and International Health Policies favoring professionals to perceive this phenomenon under a more critical and questioning point of view.

DESCRIPTORS: nursing workers; health; psychoactive substance; nursing

\section{EL TRABAJO CON SUBSTANCIAS PSICOACTIVAS: EL SIGNIFICADO PARA EL TRABAJ ADOR DE ENFERMERÍA}

En este estudio yo me he propuesto a comprender el significado del trabajo con substancias psicoactivas para los trabajadores de enfermería de la clínica médica de un hospital. Para lograr tal intento, fueron utilizadas algunas ideas del referencial metodológico fenomenológico. Se realizó entrevistas a partir de la cuetión orientadora"lo que es para usted trabajar con substancias psicoactivas?". El análisis de los discursos revelo que tal labor se mostra a los obreros, en su esencia, un trabajo"como cualquier otro", siendo significativo el énfasis dado al hacer en detrimento de la práctica reflexiva; el temor de hablar sobre"el prohibido", lo que"compromete", siendo la droga enfocada como una posibilidad real de uso en el cotidiano de los obreros. Sus experiencias reafirman la necesidad de se reflexionar y discutir sobre el fenómeno drogas, articulando las vivencias intersubjetivas al contexto de las Políticas Nacionales e Internaconales de Salud, favorecendo a los profesionales la percepción del fenómeno de manera crítica e inquisidora.

DESCRIPTORES: trabajador de enfermería; salud; substancia psicoactiva; enfermería

\footnotetext{
${ }^{1}$ As opiniões expressas neste artigo são de responsabilidade exclusiva dos autores e não representam a posição da organização onde trabalham ou de sua administração; ${ }^{2}$ Professor Assistente da Faculdade de Enfermagem da Universidade do Estado do Rio de Janeiro, e-mail: ogresrose@uol.com.br; ${ }^{3}$ Docente da Escola de Enfermagem de Ribeirão Preto, da Universidade de São Paulo, Centro Colaborador da OMS para o desenvolvimento da pesquisa em enfermagem, e-mail: adricor@eerp.usp.br
} 
O consumo de drogas aparece como um dos problemas que mais tem despertado interesse e preocupação nas últimas décadas.

O homem pela sua própria natureza tem buscado, através dos tempos, alternativas para aumentar seu prazer e diminuir o sofrimento. De início, os chás, os fumos mágicos, os óleos medicinais que eram empregados de forma controlada por normas sociais e ritos tinham sempre uma função curativa, ritualística, ou mesmo mística.

A utilização de substâncias psicoativas pelo homem apresenta valores e simbolismos específicos que variam de acordo com o contexto histórico e cultural, em setores como o religioso/místico, social, econômico, medicinal, psicológico, climatológico, militar, e na busca do prazer $^{(1)}$. Portanto, o homem lança mão de veículos inebriantes para modificar e/ou alterar sua percepção e humor, tendo como conseqüência, na maioria das vezes, uma alteração do comportamento.

Minha inquietação quanto à temática drogas foi se delineando em minha prática, como enfermeira docente/ assistencial, convivendo com pessoas que lidam diariamente com substâncias psicoativas numa unidade hospitalar, onde pude perceber diferentes modos de lidar com essas substâncias, desde o simples ato de manipulação até a sua utilização pelo trabalhador. Além disso, as questões referentes à saúde do trabalhador que está lidando com essas substâncias diariamente sempre mostrou-se a mim como temática importante.

Lidar com substâncias psicoativas é uma situação complexa que envolve dimensões sociais, econômicas, políticas, familiares e individuais, considerando o contexto em que se insere o trabalhador. Apesar de os trabalhadores de enfermagem terem livre acesso a tais medicamentos,em seu cotidiano de trabalho, sendo responsáveis inclusive por sua guarda e controle, o manuseio dessas drogas parece mostrar-se somente como mais uma rotina a ser desenvolvida.

Ao longo dos anos, pude compreender a complexidade do trabalho no contexto hospitalar, sendo necessário considerar que os trabalhadores, em sua dimensão existencial, podem enfrentar momentos de dificuldades e/ou crises de variados contornos e significados, e perceberem o uso de drogas como uma possibilidade que "facilita" a condução de suas vidas cotidianas. especificamente os que trabalham em hospitais, ficam duplamente expostos; fisicamente, por exposição aos riscos de substâncias químicas, radiações, contaminações biológicas, excesso de calor, sistema de plantões e excessiva carga horária; e psiquicamente, em decorrência da convivência diuturna com o sofrimento e a dor, a doença e a morte, tendo que conviver com tais circunstâncias paralelamente aos seus problemas emocionais,podendo essas condições de trabalho favorecerem o uso de substâncias psicoativas ${ }^{(2)}$.

Esse ambiente hospitalar é um dos espaços no qual a enfermagem pode desenvolver suas atividades, permanecendo em contato direto com a doença, a morte e o sofrimento humano, por mais tempo que qualquer outra categoria profissional.

A dependência química entre médicos e profissionais de saúde já se transformou em séria preocupação das autoridades sanitárias de vários países do mundo, principalmente Estados Unidos e Inglaterra. $\mathrm{O}$ uso de substância psicoativa é progressivo e fatal. No caso dos médicos, por deteriorar o raciocínio linear, ela altera a aptidão de prescrever e administrar medicamentos, tomar decisões e executar procedimentos especializados, colocando em risco a vida dos clientes sob seus cuidados. No Brasil, a discussão está sendo apenas iniciada, mas pesquisas já demonstram a gravidade da questão ${ }^{(3)}$. Em relação ao trabalhador de enfermagem, a literatura mostra lacunas, não apontando estudos sobre o tema, daí a importância da produção científica nessa área.

O manejo de substâncias psicoativas envolve o fortalecimento da capacidade individual e coletiva no enfrentamento das frustrações do cotidiano. A freqüência do uso de droga, em maior ou menor grau, pode estar relacionado com o nível de desenvolvimento sóciocultural, de cada país; uma sociedade se torna mais vulnerável por várias razões, entre as quais o descontentamento, o ideal não alcançado, quando reina o desespero entre os indivíduos por não encontrarem seu papel social; quando predomina a injustiça ou existe o perigo iminente de um conflito social $^{(4)}$. Em épocas de aumento da exclusão social, verifica-se também um incremento na busca de soluções mágicas para os problemas, sejam elas um profeta ou qualquer outro expediente, inclusive de natureza química.

Há de se ressaltar, ainda, que existe uma certa resistência da sociedade para discutir o fenômeno das 
drogas sem preconceitos e para compreender a vivência dos usuários e suas motivações.

Segundo o Centro Brasileiro de Informações sobre Drogas Psicotrópicas (CEBRID) ${ }^{(5)}$, entre as drogas lícitas, há significativo consumo de medicamentos psicotrópicos. Essa realidade pode ser enfocada na atual conjuntura histórico-cultural, envolvendo o papel social do uso de drogas, as motivações das pessoas, bem como a postura da sociedade perante essa prática e o usuário.

A sociedade tem passado por muitas modificações nos últimos anos e isso se deve a uma gama de situações: a urbanização acentuada e desorganizada; a falta de oportunidade de desenvolvimento e emprego para todos; o desrespeito público, incluindo o próprio papel dos governos e autoridades; o fenômeno da globalização da economia, derrubando muros e mitos, porém, mantendo as desigualdades socioeconômicas; os valores que estão sendo modificados num ritmo veloz sem permitir acomodação equilibrada dos pensamentos, ações e idéias; o telejornalismo, destacando a violência que entra em nossas casas, no momento exato em que fatos dramáticos acontecem no mundo inteiro. Todas essas situações podem afetar as pessoas e contribuir para mudar seu modo de viver.

Considerando as complexas questões que envolvem o fenômeno drogas, suas implicações com o ambiente de trabalho na área da saúde e minha trajetória profissional, minha proposta é desenvolver esse tema, buscando compreender os significados que os trabalhadores de enfermagem atribuem ao lidar com substâncias psicoativas em seu cotidiano profissional, o que está relacionado ao tempo vivido por cada um, envolvendo seus sentimentos, crenças, valores, conhecimentos, enfim, suas vivências relacionadas ao fenômeno drogas no contexto atual.

\section{A TRAJETÓRIA DO ESTUDO}

Desejando compreender o que é para o trabalhador de enfermagem lidar, em seu cotidiano, com substâncias psicoativas, busquei um caminho metodológico que possibilitasse aproximar-me das vivências do profissional de enfermagem envolvendo o pensar, o sentir e o agir, com o outro, inserido em um contexto.

Para compreensão de um objeto de tal natureza, a pesquisa qualitativa de orientação fenomenológica mostrou-se como uma possibilidade, considerando que ela pode me aproximar das vivências dos trabalhadores no contexto da temática em questão, fundamentando sua proposta básica na compreensão daquilo que é vivenciado como fenômeno humano.

A pesquisa fenomenológica valoriza os significados que os sujeitos atribuem à sua experiência vivida que se revelam a partir de suas descrições. Entretanto, para o pesquisador ir ao mundo vida dos sujeitos há de adotar uma postura de"colocar entre parênteses"tudo o que pensa, seus juízos, para desvelar como as pessoas vivenciam determinadas situações ${ }^{(6)}$.

Para tal, entrevistei profissionais de enfermagem (enfermeiros, residente de enfermagem e auxiliares de enfermagem) que desenvolviam suas atividades em uma unidade de clínica médica de um Hospital Universitário,situado na cidade do Rio de Janeiro. O estudo foi realizado entre março de 2002 a julho de 2003.

Primeiramente, o projeto foi submetido à avaliação do Comitê de Ética em Pesquisa do Hospital onde o trabalho foi desenvolvido; após obter a "aprovação" desse Comitê, entrei em contato com a Coordenação de Enfermagem e a chefia de unidade de clínica médica, solicitando sua permissão para entrevistar os trabalhadores de enfermagem que aí atuam.

A obtenção das falas

Após obter a permissão do chefe de enfermagem da unidade de clínica médica, o mesmo convidou, durante cada passagem de plantão, os funcionários para participarem deste estudo.Todos os funcionários concordaram em participar da pesquisa. Agendamos as entrevistas individuais, segundo o dia e o horário de preferência de cada um, sendo que algumas foram realizadas no início do plantão, outras no final e algumas durante o plantão. Todo o processo de coleta abrangeu o período de agosto a setembro de 2002.

Considerando a proposta do estudo, utilizei a técnica de entrevista aberta com a seguinte questão: 0 que é para você lidar com substâncias psicoativas em uma unidade hospitalar?

Para se realizar uma entrevista fenomenológica, desvelando facetas do fenômeno em estudo, é imprescindível que o entrevistador esteja atento para alguns pontos: ele deve assumir atitude de sintonia com os participantes e sua condição vivencial; deve ouvir o 
respondente de forma empática, tornando-se presente nesse encontro.

As entrevistas foram realizadas em uma sala da unidade de clínica médica, após esclarecimento detalhado sobre o estudo e assinatura do Termo de Consentimento Livre e Esclarecido, conforme preconizado pelo Conselho Nacional de Pesquisa ${ }^{(7)}$.

Apesar do acesso que tenho a essa equipe, tive muitas dificuldades, pois, quando eu falava da minha vontade de trabalhar o tema, as pessoas manifestavam um ar de perplexidade e medo por terem que falar de um assunto tão difícil, complexo e preconceituoso, pois tinham receio de comprometer-se ou envolver outras pessoas.

Essas dificuldades foram percebidas quando os integrantes da equipe de enfermagem demoravam para dar início à sua fala . Sempre pediam um tempo, alegando que nunca haviam pensado nesse tema, apesar de o mesmo fazer parte de seu cotidiano profissional. Por outro lado, começavam as falas dizendo "eu não faço uso". A todo momento demonstravam um certo receio em falar sobre o fenômeno drogas, mas ao mesmo tempo gostariam que esse tema fosse mais discutido, chegando a solicitar que as entrevistas fossem realizadas em grupo.

Ao final, obtive 12 depoimentos, sendo dois de enfermeiros, um de enfermeiro residente e nove de auxiliares de enfermagem. As entrevistas foram encerradas quando as falas, consideradas em suas convergências e divergências, mostraram-se suficientes para a compreensão do fenômeno em foco, tendo em vista a interrogação do pesquisador. Suficientes no sentido de lançar luz ao fenômeno, desvelando algumas de suas facetas.

Procurei manter uma relação voltada para o fenômeno, buscando descrever e interpretar os significados da experiência vivida, com profundidade e riqueza, reintegrando as partes ao todo, o contingente e o essencial, os valores e os desejos.

Procedimento de análise das falas

A leitura atentiva foi repetida por várias vezes até que as falas se tornassem claras, tomando um sentido significativo. Emergia, então, nesse momento, a visão intersubjetiva que permitia agrupar as falas em unidades de significados.

Através de suas falas, os trabalhadores de enfermagem expressaram como lidam com as substâncias psicoativas, no cotidiano de uma unidade hospitalar, desvelando o que significa para eles lidar com o fenômeno drogas. Foi um momento que exigiu muita sensibilidade e percepção, pois, de cada palavra ou de cada silêncio, emergia um significado que, embora velado ou desvelado, ia se mostrando naquilo que expressava o ser de cada um, nesse contexto.

Foi então que, após esse momento, articulando um discurso ao outro, consegui compreender o significado próprio de cada faceta daquilo que se mostrava, configurando as unidades temáticas, as quais relaciono a seguir.

Lidar com substâncias psicoativas no contexto hospitalar é:

- Um trabalho como qualquer outro;

- A substância psicoativa como uma possibilidade de uso; - Medo em falar do tema/Assunto proibido.

\section{A COMPREENSÃO DAS FALAS}

A interpretação das falas evidencia como o lidar com e substâncias psicoativas se mostra, para os profissionais de enfermagem.

Um trabalho como qualquer outro

Os profissionais de enfermagem verbalizaram que manusear substâncias psicoativas é um trabalho como qualquer outro, conforme os trechos dos depoentes (dep.) a seguir.

... lidar com substâncias psicoativas é um trabalho como outro qualquer, independente do profissional saber que é uma droga (dep. 1).

... é um trabalho como outro qualquer, é tão importante como administrar um analgésico, pois não vejo diferença (dep.5).

Nesta unidade temática as falas dos sujeitos sugerem que os trabalhadores de enfermagem lidam com as substâncias psicoativas, fundamentados apenas no procedimento de administração de medicamentos.

... é ler a prescrição, preparar o medicamento psicotrópico e administrar. Eu pelo menos nunca parei para pensar na questão social da droga (dep.3).

Além das dificuldades que os diferentes grupos sociais têm para refletir e discutir sobre o fenômeno drogas, percebe-se que o profissional de enfermagem está 
muito preocupado com o"fazer", não refletindo também sobre as diversas implicações do lidar com a substância psicoativa.

Esse fazer mecanicista, fruto da fragmentação do trabalho, no contexto da saúde, além de dificultar a reflexão sobre a sua própria prática, funciona muitas vezes, como meio de tolerar os temores, medos e frustrações que envolvem a experiência de cuidar do outro.

A enfermagem constitui o grupo de trabalhadores de maior vulto nas instituições hospitalares; é depositária não só das rotinas e procedimentos como também dos sentimentos dos que aí circulam. Para o enfermeiro, este é um ponto crucial uma vez que, pelas características do seu trabalho, tem oportunidade de conviver com várias pessoas, compartilhando dores e sofrimentos e, deste modo, envolvendo-se com a fragilidade humana. É preciso enfatizar, ainda, que inúmeros mecanismos de defesa foram sendo incorporados à organização do trabalho dos enfermeiros ao longo da história, tendo como principal finalidade o controle das emoções, visando diminuir a ansiedade e viabilizar a assistência com produtividade ${ }^{(8)}$.

No cotidiano, prestando assistência ao cliente, o profissional de enfermagem fica tão envolvido no fazer, em atender aquilo que considera como necessidades básicas do cliente, ou até no cumprimento das tarefas préestabelecidas, que perde a noção do que o envolve. Ele, no seu fazer, administra as mais variadas medicações e não percebe que algumas são substâncias psicoativas que podem levar à dependência química.

A substância psicoativa como uma possibilidade de uso

Em suas falas está implícito e, às vezes, explícito, que o profissional de enfermagem "tem conhecimento" que outros trabalhadores podem se utilizar de drogas no contexto de trabalho,tornando evidente que relegam sua formação ética, revelando, porém, que a aproximação ao uso de droga é realmente uma experiência vivida que extrapola a lógica conceitual/racional que aponta o certo e o errado, como as seguintes falas:

... a pessoa que está buscando a droga não está raciocinando como profissional, é uma pessoa que está em desespero, procurando uma forma de aliviar um sofrimento, uma dificuldade (1).

... eu já até ouvi um profissional de enfermagem comentando que fez uso de um determinado psicotrópico por conta própria durante um plantão por estar se sentindo deprimida (4).
O trabalho constitui um valor importante na vida da pessoa e deve ser considerado e analisado amplamente para que as diferentes problemáticas que ocorrem no seu contexto possam ser compreendidas; é inegável que o trabalho, conforme compreendido na atualidade, exerce notável influência sobre a ação humana, pois a pessoa que trabalha enfrenta pressões constantes, tanto nas organizações como na sociedade ${ }^{(9)}$.

O trabalhador de enfermagem, hoje, enfrenta uma diversidade de situações, tanto em sua vida pessoal como profissional relacionada às dificuldades econômicas, aos transtornos do ritmo acelerado da vida urbana geradores de estresse físico e emocional, ao lidar constantemente com a dor e o sofrimento, às jornadas ocupacionais repetidas e intensivas, defrontando-se em seu trabalho, com uma possibilidade concreta e que, de certo modo, pode aliviar, para alguns, algumas tensões, como essas falas denotam:

... como essas substâncias se mostram de maneira fácil a nós e que somos pessoas como qualquer um vivenciando momentos difíceis em nosso cotidiano pessoal e profissional (dep.1).

... um caso foi constatado de dificuldades vivenciadas por um profissional em lidar com substâncias psicoativas, diante a fragilidade do ser humano (dep.2).

...até sei de alguns casos de profissionais que usam substâncias psicoativas, até mesmo durante os plantões (dep.9).

Obviamente, o uso de drogas envolve sempre a singularidade do sujeito, seu modo de lidar com as situações cotidianas, porém, não dá para sermos ingênuos acreditando que o profissional da saúde está "imune" em relação a essas situações. Na verdade, ele vivencia sua situação singular sempre inserido em um contexto e, nesse sentido, a problemática "drogas" não comporta apenas uma decisão individual, mas, como já comentado, em sua complexidade, como fenômeno humano, reveste-se de múltiplas dimensões- econômicas, políticas, sociais, culturais, existenciais.

O profissional, apesar de falar pouco sobre o tema e vivenciar um cotidiano de trabalho eminentemente "tarefeiro" e pouco reflexivo, consegue perceber a complexidade e a possibilidade do uso de drogas, associando a vida moderna, marcada por situações que podem gerar sofrimento, com a possibilidade de fuga da "dor" de existir. Ou seja, "ser no mundo", constituir sua própria existência, no contexto atual, é uma árdua tarefa para o homem, cercada de dúvidas e limites. Ao mesmo tempo, o trabalhador demonstra uma fragilidade e até 
impotência diante das situações, como esses discursos evidenciam:

...de repente tem até alguém aqui que faz uso, que tem alguma dificuldade em sua vida pessoal e a gente não pensa no que isso pode significar (dep.3).

... até mesmo no plantão noturno pode ter alguém deprimido e queira fazer uso. Na realidade nunca parei para pensar na droga (dep.4).

Nas falas emerge que os profissionais de enfermagem sabem de situações em que se usam drogas, inclusive no cotidiano de trabalho. A complexidade do tema e a fragilidade de cada pessoa se fazem presentes em seu discurso. Compreendo que o importante é buscar o sentido da droga e como lidar com esse fenômeno. É necessário pensar na qualidade de vida do trabalhador de enfermagem e nas suas implicações para assegurar um bom atendimento, pois ele também lida com o sofrimento do outro e isso exige condições relacionadas às esferas afetivas e práticas para as quais o trabalhador de enfermagem pode não estar preparado.

Medo em falar do tema/assunto proibido

Apesar de lidar com substâncias psicoativas em seu cotidiano como profissional de enfermagem, e até vivenciar situações sociais diversas como o uso e abuso de drogas por familiares ou pessoas próximas, e também, a própria violência, muitas vezes decorrentes do uso dessas substâncias, os trabalhadores mostram ter medo de tocar no assunto que parece proibido, revelando-se até comprometedor.

...estamos percebendo toda a fragilidade que temos em lidar com ela, pois temos dificuldade até em falar, pois se pensa que você está fazendo uso (dep.9).

...carregamos conosco o medo de estarmos lidando com ela ou de estarmos falando delas (dep.9).

Nesses relatos, percebo que, embora o fenômeno drogas seja uma realidade nos dias atuais, tendo invadido o espaço de muitas famílias, a temática ainda é cercada de temores e preconceitos até mesmo entre os profissionais da área de saúde. O que nos chama a atenção em alguns relatos é que se substitui a palavra droga por "ela", tentando talvez esconder o vivido e mostrar um "afastamento protetor" em relação à questão.

Prevalece nessas falas o temor, velado, recriminado e, algumas vezes, até fruto de situações punitivas, ficando caracterizada a complexidade do lidar com este fenômeno, como mostra esta fala:

... já houve casos de profissionais de enfermagem serem punidos por fazerem uso de substâncias psicoativas (dep.3).

Nesta descrição, é revelado que, às vezes, no contexto ocupacional, existe um modo exclusivamente punitivo de lidar com o problema, levando cada vez mais a temores em relação ao assunto drogas, não sendo abordado como um fenômeno concreto, necessitando de reflexão e discussão no âmbito da formação e da gestão do trabalho.

A possibilidade do uso da droga revela a nossa fragilidade humana, a incontrolável insegurança quanto ao próprio existir, considerando que viver é um ato empreendido a cada momento, estando sujeito a dores e sofrimentos, os quais, muitas vezes, não somos capazes de suportar/enfrentar.

A insegurança do existir humano é uma condição ontológica, um modo de ser humano que, todavia, vem sendo enfocado, pela episteme ocidental, como algo a ser vencido e controlado ${ }^{(10)}$.

Vale acrescentar, todavia, que os profissionais de saúde que fazem uso de drogas têm consciência, pela sua própria formação, de que estão cometendo falhas no ambiente de trabalho, entretanto, não conseguem controlar suas ações. Os colegas têm conhecimento deste fato e, por isso, preferem nada comentar ou se o dizem é através de linguagem figurada tentando preservar a imagem da profissão e do colega. Poucas são as pessoas que, de fato, irão tomar uma posição diante desse ao assunto, a não ser quando não der mais para disfarçar pelas próprias implicações que a temática comporta.

Cabe considerar o despreparo da instituição para lidar com o trabalhador como um ser humano e com a temática em questão.

\section{REFLEXÕES SOBRE O ESTUDO}

Comecei este estudo propondo-me a lançar um olhar atentivo para o profissional de enfermagem que manipula substâncias psicoativas, em seu cotidiano, como trabalhadores em uma unidade hospitalar, buscando compreender o significado por ele atribuído a essa vivência.

Este caminhar ocorreu de forma intrínseca à minha prática na enfermagem como enfermeira docenteassistencial. Portanto, já havia um envolvimento profissional com a temática e com os sujeitos deste estudo, o que 
me despertou inquietações.

Retomando minha interrogação inicial, visualizo que a trajetória percorrida revelou algumas facetas vividas pelo profissional de enfermagem ao trabalhar com substâncias psicoativas, através de suas falas. Considero que este caminhar orientado por algumas idéias do referencial teórico-metodológico da fenomenologia constituiu-se na chave para a compreensão de algumas facetas do fenômeno em questão.

Os nossos encontros possibilitaram a emergência de sentimentos, significados, pensamentos, opiniões, o compartilhamento de dúvidas, incertezas, temores e preconceitos em relação às suas vivências.

Como professor, nas atividades em uma unidade hospitalar, tenho a preocupação de buscar também a dimensão humana na formação da "competência" do aluno para além da competência técnica, uma vez que esta é necessária, porém não é suficiente quando nos dispomos a cuidar de outros seres humanos.

Através das falas, pude compreender que, para os sujeitos do estudo, lidar com substâncias psicoativas era um procedimento como outro qualquer e um trabalho automático. Relataram, também, receio em falar sobre "o proibido" e "o que compromete", mecanismo de defesa incorporado ao fazer da enfermagem que, numa linha tradicionalista, tem exigido de seus trabalhadores 0 controle das emoções e ansiedade, impedindo o desvelar dos significados de suas vivências. Por outro lado, à medida que falavam sobre suas vivências relacionadas ao fenômeno drogas, reconheciam a importância de refletir e discutir sobre o tema.

Compreendo que esses trabalhadores não estejam preparados para enfrentar situações que envolvam as drogas psicoativas. Torna-se necessário repensar na formação dos profissionais de enfermagem com uma preocupação social crescente, considerando os problemas ocasionados pelo consumo excessivo de substâncias químicas. Os currículos devem contemplar a discussão do tema, conforme as políticas nacionais e internacionais de saúde, estimulando os futuros profissionais a perceberem de forma mais consciente e crítica esse fenômeno e suas conseqüências.

Tem havido um crescente interesse público e governamental pelos problemas relacionados ao uso e abuso de substâncias psicoativas lícitas e ilícitas. Esse interesse tem sido despertado pelo peso significativo dos problemas sociais decorrentes do aumento do consumo de substâncias psicoativas pela população, tais como a criminalidade, a violência e a mortalidade por causas não naturais. Entretanto, as substâncias psicoativas estão presentes no cotidiano das sociedades humanas e, também, no dia-a-dia do profissional de enfermagem,mesmo que não percebam isso como concreto.

A realização deste estudo reafirmou a minha convicção quanto à importância do trabalhador de enfermagem rever suas próprias crenças, valores e preconceitos em relação às substâncias psicoativas, buscando a atualização do conhecimento nessa área numa perspectiva interdisciplinar.

É necessário criar atividades de auto-avaliação contínua da prática profissional, a supervisão de outro profissional de saúde capacitado e, algumas vezes, a terapia individual ou grupal para desvelar emoções e sentimentos que possam estar inconscientes e precisam ser trabalhados para transformarem nossas atividades rotineiras em ações humanizadas.

É preciso refletir sobre o fenômeno drogas para que se possa desenvolver trabalhos sob diferentes perspectivas, oportunizando aos profissionais de enfermagem sua melhor compreensão e conseqüentemente facilitando o lidar com essa questão. Não dá para reduzir a problemática, temos que estar atentos a todas as suas dimensões sociais,econômicas e culturais, políticas e existenciais.

\section{AGRADECIMENTOS}

Agradecemos a todos os docentes da Escola de Enfermagem de Ribeirão Preto e aos trinta e três participantes de nove países latino-americanos que participaram do processo de implementação dos dois programas, e também ao Governo do Japão e ao Programa de Bolsas da OEA por seu apoio financeiro e bolsas que possibilitaram a implementação do "I Programa Regional de Capacitação em Pesquisa para Enfermeiros da América Latina". 


\section{REFERÊNCIAS BIBLIOGRÁFICAS}

1. Lessa MBMF. Os paradoxos da existência na história do uso das drogas. [online]. [acessado 20 jul. 2003]. Disponível em: URL: Internet,IFEN.me//C.WINDOWS/TEMP/existência e drogas 2003.nun

2. Camarotti H,Teixeira HA. A saúde mental e trabalho: estudo da regional norte de saúde do DF. Rev Saúde Pública 1996 janeiro/março; 7(1):35-46.

3. Bou Habib JC, Dunn J, Laranjeiras R. Dependência química entre os profissionais de saúde. Rev Cons Fed de Med 1998 abri; 12(92):18-25.

4. Varenne G. El abuso de las drogas. Madrid (Es): Ed. Guanabara; 1973.

5. CEBRID. Sugestões de prevenção ao uso indevido de drogas. São Paulo (SP): Departamento de Psicologia da Universidade Federal de São Paulo; 1995.

6. Capalbo C. Fenomenologia e ciências sociais. Londrina (PR): UEL; 1996.

7. Ministério da Saúde (BR). Diretrizes e normas regulamentadoras de pesquisa envolvendo seres humanos. Brasília (DF): Ministério da Saúde; 1998.

8. Ferreira NMLA. O câncer e o doente oncológico segundo a visão de enfermeiros. Rev Bras Cancerol 1996 março; 42(3):161-70.

9. Lautert I .O desgaste profissional do enfermeiro. [Tese]. Salamanca (Es): Faculdade de Psicologia Universidade Pontifícia de Salamanca; 1995.

10. Critelli DM. Analítica do sentido: uma aproximação e interpretação do real de orientação fenomenológica. São Paulo (SP): EDUC/Brasiliense; 1996. 